\title{
Effects of type and concentration of alginate on microencapsulation characteristics of lime essential oil (Citrus aurantifolia) produced by extrusion-dripping methods
}

Vinh Truong*, Phuong T. Nguyen, Phuong N. M. Ta, Phuong T. Nguyen, \& Nhung T. C. Pham

Department of Chemical Engineering, Nong Lam University, Ho Chi Minh City, Vietnam

\author{
ARTICLE INFO \\ Research Paper \\ Received: November 12, 2019 \\ Revised: December 15, 2019 \\ Accepted: January 02, 2020 \\ Keywords \\ Alginate \\ Extrusion-dripping method \\ Ion-gel \\ Lemon oil \\ Microencapsulation \\ ${ }^{*}$ Corresponding author \\ Truong Vinh \\ Email: tv@hcmuaf.edu.vn
}

ABSTRACT

The extrusion-dripping method to produce alginate-calcium beads for microencapsulation of lime oil (Citrus aurantifolia) was carried out in this study. The experimental range of alginate concentration was from 1 to $4 \%$. Above $1 \%$ alginate concentration, viscosity was pseudoplastic behavior. The size $(1.52-1.57 \mathrm{~mm})$ and sphericity (above $95 \%$ ) of the beads were maximum at alginate concentration of $2-3 \%$. The extrusion-dripping method was not applicable when alginate concentration was over $3.5 \%$ due to the high viscosity resulting in low sphericity. The two types of alginates with a protein content of $9 \%$ (alg1) and $2 \%$ (alg2) had the same microencapsulation yield of $73-74 \%$. However, the solid recovery of alg2 (98.99\%) was much higher than that of alg1 $(52.71 \%)$. This is because alg2 has a higher purity and if it is used in production, it is easier to control the content of active ingredients and reduce the amount of organic waste that is harmful to the environment compared to alg1.

Cited as: Truong, V., Nguyen, P. T., Ta, P. N. M., Nguyen, P. T., \& Pham, N. T. C. (2020). Effects of type and concentration of alginate on microencapsulation characteristics of lime essential oil (Citrus aurantifolia) produced by extrusion-dripping methods. The Journal of Agriculture and Development 19(1), 65-76. 


\title{
Ảnh hưởng của loại và nồng độ alginate lên đặc tính vi bọc tinh dầu chanh (Citrus aurantifolia) bằng phương pháp nhỏ giọt kim tiêm
}

\author{
Trương Vĩnh*, Nguyễn Thanh Phương, Tạ Ngọc Minh Phương, \\ Nguyễn Thành Phương \& Pham Thị Cẩm Nhung
}

Bộ Môn Công Nghệ Hóa Học, Trường Đại Học Nông Lâm TP.HCM, TP. Hồ Chí Minh

\section{THÔNG TIN BÀI BÁO}

Bài báo khoa học

Ngày nhận: 12/11/2019

Ngày chỉnh sửa: 15/12/2019

Ngày chấp nhận: 02/01/2020

Từ khóa

Alginate

Ion-gel

Phương pháp nhỏ giọt

Tinh dầu chanh

Vi bọc

*Tác giả liên hệ

Trương Vĩnh

Email: tv@hcmuaf.edu.vn

\section{TÓM TẮT}

Vi bọc tinh dầu chanh bằng phương pháp nhỏ giọt kim tiêm tạo hạt Alginate-Ca đã được thực hiện trong nghiên cứu này. Khoảng nồng độ alginate khảo sát là 1 - 4\%. Ở nồng độ alginate trên $1 \%$, dịch có độ nhớt dạng pseudoplastic. Kích thước $(1,52-1,57 \mathrm{~mm})$ và độ cầu hạt (trên $95 \%$ ) đạt cực đại ở nồng độ alginate 2 - 3\%. Phương pháp nhỏ giọt kim tiêm không phù hợp khi nồng độ alginate trên 3,5\% do độ nhớt dịch quá cao dẫn đến độ cầu thấp. Hai loại alginate của Trung Quốc có hàm lượng đạm $9 \%$ (alg1) và $2 \%$ (alg2) có cùng hiệu suất vi bọc $73-74 \%$. Tuy nhiên, hiệu suất thu hồi chất rắn alg2 đạt 98,99\% cao hơn nhiều so với alg1 chỉ 52,17\%. Điều này do alg2 có độ tinh khiết cao hơn và nếu chọn sử dụng trong thực tế sản xuất thì dễ kiểm soát hàm lượng và giảm lượng chất thải hữu cơ gây hại môi trường so với alg1.

\section{1. Đặt Vấn Đề}

Vi bọc (microencapsulation) là một quá trình bọc (bao) một chất trong một chất khác để tạo ra các hạt, phần tử có đường kính vài nanometer $(\mathrm{nm})$ đến vài millimeter $(\mathrm{mm})$. Vi bọc nhằm bảo vệ các vật liệu (hoạt chất, xúc tác) khỏi sự tác động của môi trường từ đó tăng thời hạn sử dụng trong bảo quản, giảm hư hỏng sản phẩm trong chế biến. Ngoài ra vi bọc còn giúp kiểm soát tốc độ phóng thích hoạt chất theo mong muốn. Công nghệ vi bọc được áp dụng rộng rãi trong các lĩnh vực dược phẩm, mỹ phẩm, thực phẩm, thuốc bảo vệ thực vật, phân bón. Các chất xúc tác như enzyme, vi khuẩn, nấm, xúc tác hóa học (sinh học) khi được vi bọc có thể tái sử dụng nhiều lần. Các hoạt chất như chất chống oxy hóa, hương liệu, dầu thực vật, vitamin, amino acid, chất màu, thuốc nhuộm, dễ bị hư hỏng do sự tác động của môi trường bên ngoài như ánh sáng, ẩm độ, nhiệt độ, oxygen, hoặc do phản ứng với các hóa chất khác, sẽ được tránh khỏi khi các vật liệu đó được chế tạo dưới dạng vi nang.

Các tinh dầu đã được chứng minh là có tính diệt khuẩn và có thể ứng dụng trong thuốc bảo vệ thực vật (Anitha \& ctv., 2011), mỹ phẩm (Martins \& ctv., 2014). Soliman \& ctv. (2013) đã nghiên cứu vi bọc tinh dầu quế (Cinnamon), đinh hương (Clove) \& húng tây (Thyme) với hiệu suất vi bọc $90-94 \%$ và khả năng tải $22-24 \%$ bằng phương pháp ion-gel hệ Alginate-Ca dùng vòi phun khuếch tán để tạo giọt.

Tinh dầu chanh được sử dụng làm hương liệu trong thực phẩm, dược phẩm và mỹ phẩm dưới dạng vi bọc (Martins \& ctv., 2014). Tinh dầu chanh được vi bọc bằng nhiều phương pháp như trùng hợp (polymerization) sử dụng ureaformaldehyde (Park \& ctv., 2001), kết tụ phức (complex coacervation) sử dụng hai polymer là whey protein và gum arabic (Weinbreck \& ctv., 
2004) và bằng sấy phun với khả năng tải tinh dầu là 10\% (Kausadikar \& ctv., 2015) nhưng chưa có nghiên cứu vi bọc tinh dầu chanh bằng phương pháp ion-gel. Phương pháp ion-gel hệ AlginateCa có cơ chế là tạo liên kết giữa ion âm của alginate với ion dương của calcium để vi bọc hoạt chất đã khuếch tán trong alginate, được chọn trong nghiên cứu này.

Nguyên lý tạo hạt kiểu nhỏ giọt (extrusiondripping methods) có thể được thực hiện bằng tạo giọt đơn giản dùng vòi tiêm, bằng tĩnh điện (electrostatic) hoặc rung dòng tia (vibrational jetbreakup). Phương pháp nhỏ giọt đơn giản từng giọt được đẩy ra khỏi vòi tiêm và rơi vào bể tạo gel được ứng dụng trong nghiên cứu này nhằm khảo sát ảnh hưởng của chất lượng và nồng độ alginate lên đặc tính hạt vi bọc tinh dầu chanh. Alginate là một họ polysaccharide ion âm mạch thẳng, là copolymer của $\alpha$-L-guluronic acid $(\mathrm{G})$ và $\beta$-D-mannuronic acid $(\mathrm{M})$ và cấu trúc hóa học không có nguyên tố N (Wandrey \& ctv., 2010). Nếu trong thành phần nguyên liệu alginate có $\mathrm{N}$ chứng tỏ có các tạp chất và sẽ ảnh hưởng đến quá trình vi bọc vì protein không tham gia vào liên kết ion và sẽ tan vào trong nước nên có thể cản trở quá trình vi bọc và tạo thành nguồn thải. Việc khảo sát ảnh hưởng của chất lượng alginate đặt ra do trên thị trường Việt Nam có nhiều loại alginate của Trung Quốc có độ tinh khiết khác nhau.

\section{Vật Liệu và Phương Pháp Nghiên Cứu}

\subsection{Vật liệu}

Tinh dầu chanh có nguồn gốc chiết xuất tự nhiên từ vỏ chanh tươi (chanh sần, citrus aurantifolia) và cung cấp bởi công ty Tinh dầu Thiên nhiên, Việt nam, ở địa chỉ 51/4 Phú Mỹ, Quận Bình Thạnh, TP.HCM. Sodium Alginate của Trung Quốc gồm 2 loại Alg1 (Fooding Group Limited, màu vàng nâu, ẩm $9,9 \%$, protein $8 \%$, độ nhớt thấp) và Alg2 (Yantai Zhouji Marine Biotechnology Co., Ltd., có màu trắng, ẩm $9 \%$, protein $2,4 \%$, dộ nhớt cao). Sodium citrate, $\mathrm{CaCl} 2$ và hexan của Trung Quốc.

\subsection{Phương pháp tiến hành}

\subsubsection{Tạo hạt vi bọc}

Dùng kỹ thuật đùn nhũ tương theo phương pháp Chan \& ctv. (2011) với vài cải biên. Pha

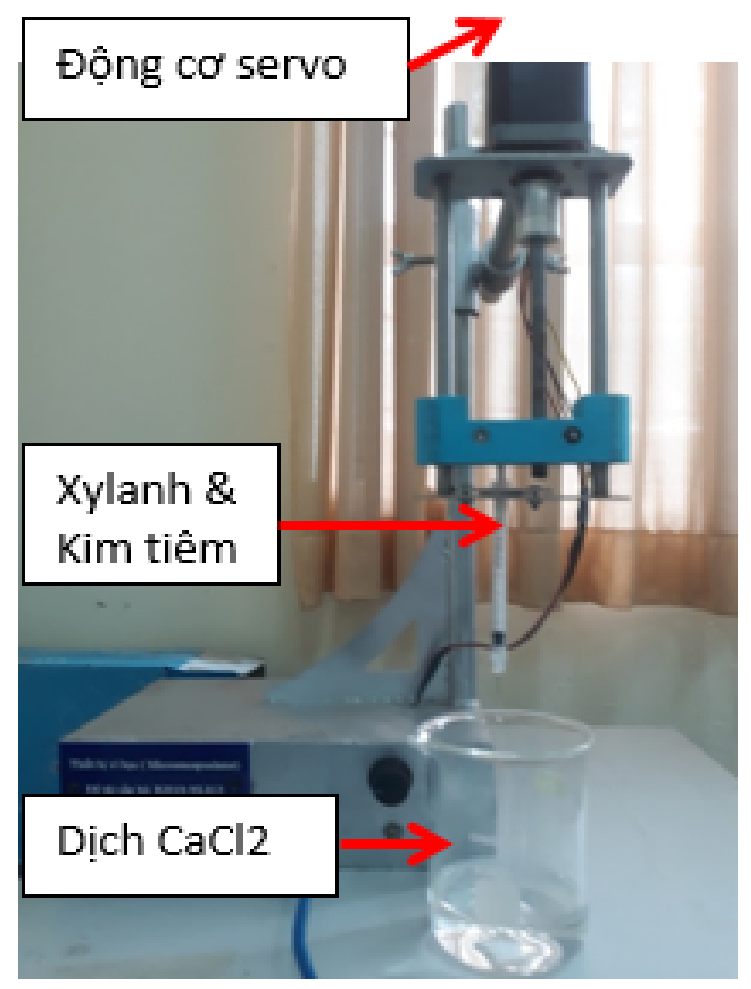

Hình 1. Thiết bị nhỏ giọt kim tiêm điều khiển bằng động cơ servo tự chế.

$100 \mathrm{~mL}$ Alginate trong nước cất có nồng độ cho trước đã hòa tan Tween 80 theo $1 \%$ tinh dầu. Cho tinh dầu từ từ vào bình alginate có khuấy từ $300 \mathrm{v} / \mathrm{p}$. Lượng tinh dầu cho vào được cố định ở năng suất tải lý thuyết $\left(\mathrm{LC}_{\mathrm{lt}}=\right.$ tinh dầu $/(\operatorname{tinh}$ dầu + Alginate $+\mathrm{CaCl}_{2}+$ Tween) là $22 \%$. Hệ nhũ tương được đồng hóa $13500 \mathrm{v} / \mathrm{p}$ bằng máy khuấy từ cơ học (Phillips HR1607) 3 phút.

Bơm nhũ tương Alginate-tinh dầu vào bình 250 $\mathrm{mL}$ chứa $\mathrm{CaCl}_{2} \quad 0,5 \%(15 \mathrm{mM})$ bằng kim tiêm có kích thước 0,26/0,51 mm (ID/OD) với lưu lượng điều khiển bằng động cơ servo sao cho đầu kim tạo ra từng giọt (thiết bị tự chế - Hình 1). Khoảng cách đầu kim tiêm đến bề mặt bể $\mathrm{CaCl}_{2}$ là $7 \mathrm{~cm}$, khuấy từ dịch $\mathrm{CaCl}_{2}$ liên tục, thời gian phản ứng 25 phút. Cho hạt ra vợt để trên giấy thấm 10 phút để xác định kích thước, hiệu suất vi bọc, hiệu quả vi bọc, năng suất tải thực tế (LC), hiệu suất thu hồi chất rắn.

\subsection{2. Đo độ nhớt dịch}

Dịch Alginate pha theo các nồng độ trước khi đồng hóa được đo độ nhớt ở $25^{\circ} \mathrm{C}$ bằng máy đo Brookfield, ở nồng độ 1 - 2,5\% dùng spindle RV3 
và ở nồng độ 3 - 4\% dùng spindle RV5. Chỉ số độ đặc $\mathrm{m}$ và chỉ số đặtc tính dòng chảy $\mathrm{n}$ tính theo phương trình sau, với $\mathrm{N}$ là số vòng quay của spindle, và $\mu \mathrm{A}$ là độ nhớt biểu kiến.

$$
\begin{aligned}
\log (\mu \mathrm{A})= & n \log \left(\frac{1}{\mathrm{n}}\right)+\log (\mathrm{m}) \\
& +(\mathrm{n}-1) \log (4 \pi \mathrm{N})
\end{aligned}
$$

\subsection{3. Đo sức căng bề mặt dịch}

Dịch Alginate pha theo các nồng độ trong ba trường hợp Alginate + nước, Alginate + nước + Tween 80 , Alginate + nước + Tween $80+$ tinh dầu chanh (tải $22 \%$ ) được đo sức căng bề mặt bằng phương pháp ống mao dẫn dùng kim tiêm có kích thước $0,26 / 0,51 \mathrm{~mm}$ (ID/OD) và cân giọt bằng cân 4 chữ số.

\subsection{4. Đo kích thước hạt}

Hạt vi bọc được đo kích thước bằng kính hiển vi Leica DM2500P. Đường kính tương đương từng hạt di, đường kính trung bình Sauter $\mathrm{d}_{3,2}$ từ 30 hạt và độ cầu $\phi$ tính theo các công thức sau (Mohsenin, 1970), với a là chiều lớn nhất, b là chiều bé nhất của một hạt. Vì hạt tạo từ giọt có dạng giọt nước khi rơi xuống nên a chiều theo phương thẳng đứng của giọt và hai chiều kia giả thiết bằng $\mathrm{b}$ :

$$
\begin{gathered}
\mathrm{d}_{\mathrm{i}}=\sqrt[3]{a b^{2}} \\
\phi_{\mathrm{i}}=\frac{\mathrm{d}_{\mathrm{i}}}{\mathrm{a}} \\
\phi=\Sigma \phi_{\mathrm{i}} / \mathrm{n} \\
\mathrm{d}_{3,2}=\frac{\mathrm{d}_{1}^{3}+\mathrm{d}_{2}^{3}+\ldots+\mathrm{d}_{\mathrm{n}}^{3}}{\mathrm{~d}_{1}^{2}+\mathrm{d}_{2}^{2}+\ldots+\mathrm{d}_{\mathrm{n}}^{2}}
\end{gathered}
$$

Ngoài ra còn tính độ cầu theo Chan \& ctv. (2009) như sau:

$$
\phi_{\mathrm{i}}=1-(\mathrm{a}-\mathrm{b}) /(\mathrm{a}+\mathrm{b})
$$

\subsubsection{Phân tích tinh dầu chanh bằng quang phổ}

Pha tinh dầu chanh trong hexan theo các nồng độ khác nhau. Để tìm bước sóng cho độ hấp thu cực đại, mẫu pha $0,1 \mathrm{~g}$ tinh dầu/10 $\mathrm{mL}$ hexan được quét ở các bước từ 290 đến $315 \mathrm{~nm}$. Thiết bị sử dụng là máy quang phổ Hewlett Packard UV-Vis. Sau đó dựng đường chuẩn hấp thu tinh dầu chanh ở bước sóng hấp thu cực đại.

\subsubsection{Xác định hiệu suất vi bọc (MEY)}

Cân $\mathrm{m}_{1}$ gram hạt tươi (khoảng $1 \mathrm{~g}$ ), cho vào dịch citrate $0,055 \mathrm{M}$, votex dến tan, cho $10 \mathrm{~mL}$ hexan vào và votex trong 3 phút. Ly tâm 6000 v/p trong 10 phút tách lớp, lấy hexan ở trên đo quang phổ, tính được lượng tinh dầu vi bọc $\mathrm{m} 0$. Hiệu suất vi bọc tính theo công thức sau, với $\mathrm{m}_{2}$ là lượng tinh dầu ban dầu trong nhũ tương Alginate- $\mathrm{CaCl}_{2}$.

$$
\operatorname{MEY}(\%)=\mathrm{m}_{0} / \mathrm{m}_{2} \times 100
$$

\subsubsection{Hiệu quả vi bọc (MEE)}

Cân $\mathrm{m}_{1}$ gram hạt tươi (khoảng $1 \mathrm{~g}$ ), chao trong hexan 30 giây để loại tinh dầu bề mặt, cho vào dịch citrate, votex. Các bước còn lại như mục hiệu suất vi bọc, xác định được khối lượng tinh dầu trong hạt $\mathrm{m}_{\mathrm{t}}$

$$
\operatorname{MEY}(\%)=\mathrm{m}_{\mathrm{t}} / \mathrm{m}_{2} \times 100
$$

2.2.8. Hiệu suất thu hồi chất rắn (YE)

$$
\mathrm{YE}(\%)=\frac{\text { KL hạt thu được }}{\text { KL nguyên liệu ban đầu }} \times 100
$$

KL: Khối lượng

2.2.9. Năng suất tải thực tế (LC)

Hạt tươi (10) và hạt khô (11), $\mathrm{m}_{1 \mathrm{~d}}$ là khối lượng hạt khô.

$$
\begin{aligned}
& \mathrm{LCw}=\mathrm{m}_{0} / \mathrm{m}_{1} \\
& \mathrm{LCd}=\mathrm{m}_{0} / \mathrm{m}_{1 \mathrm{~d}}
\end{aligned}
$$

\subsection{Các thí nghiệm}

Các thí nghiệm bao gồm khảo sát ảnh hưởng của nồng độ Alginate đến độ nhớt dịch, kích thước và độ cầu hạt vi bọc (dùng alg2); so sánh hai nguyên liệu Alg1 và Alg2 lên chất lượng hạt vi bọc (bao gồm hiệu suất, hiệu quả, năng suất tải và hiệu suất thu hồi chất rắn).

\section{Kết Quả và Thảo Luận}

\subsection{Chọn bước sóng và dựng đường chuẩn}

Độ hấp thu tinh dầu chanh trong hexan ở các bước sóng khác nhau cho trên Hình 2. Độ hấp 


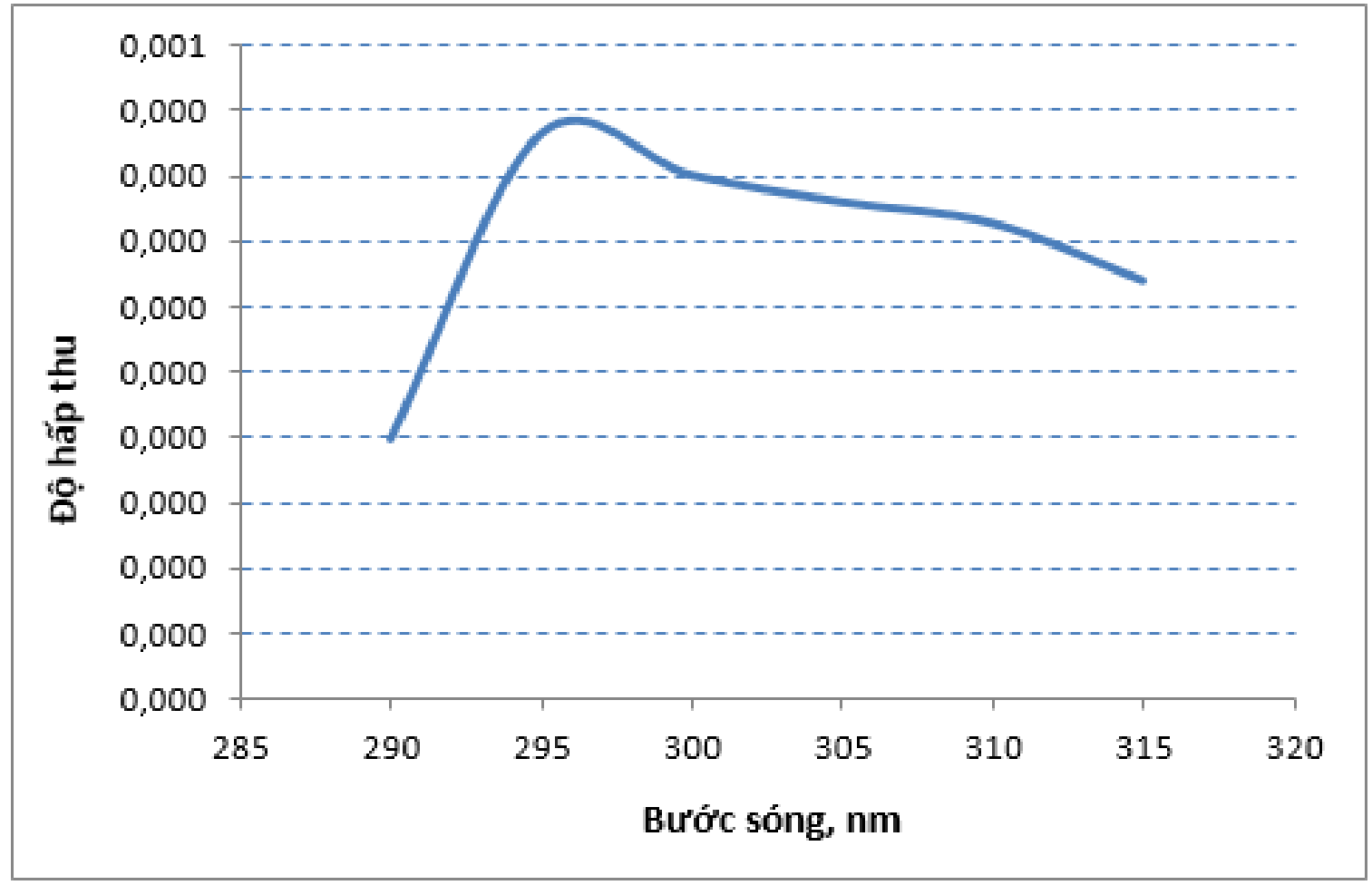

Hình 2. Độ hấp thu của tinh dầu chanh trong hexan, đạt cực đại ở bước sóng 295 nm.

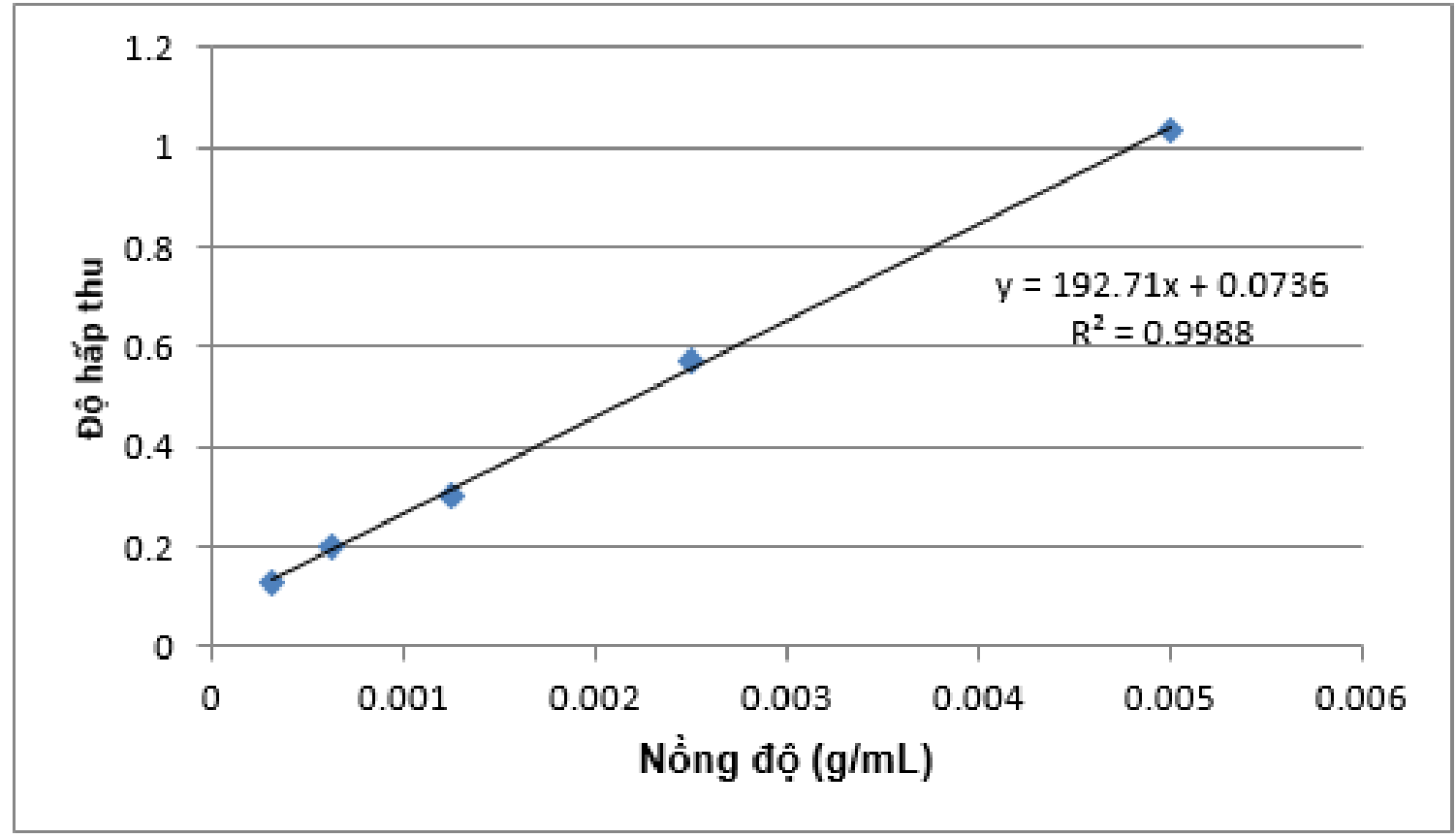

Hình 3. Đường chuẩn độ hấp thu tinh dầu chanh ở bước sóng $295 \mathrm{~nm}$. 
Bảng 1. So sánh độ nhớt dịch alginate

\begin{tabular}{ccccc}
\hline $\begin{array}{c}\text { Nồng độ Alginate, } \\
\% \mathrm{w} / \mathrm{v}\end{array}$ & $\begin{array}{c}\text { Tốc độ cắt, } \\
1 / \mathrm{s}\end{array}$ & Bratislava $^{(1)}$ & $\begin{array}{c}\text { Độ nhớt, } \\
\text { mPas Brussels }\end{array}$ & $\begin{array}{c}\text { Nghiên cứu } \\
\text { này }\end{array}$ \\
\hline 1 & 10 & 140 & 155 & 215 \\
2 & 1 & 1232 & 1334 & 1983 \\
4 & 10 & 10560 & 12587 & 16355 \\
\hline
\end{tabular}

(1): Theo Prüße \& ctv. (2008), nhiệt độ $30^{\circ} \mathrm{C}$; (2): Nhiệt độ $25^{\circ} \mathrm{C}$.

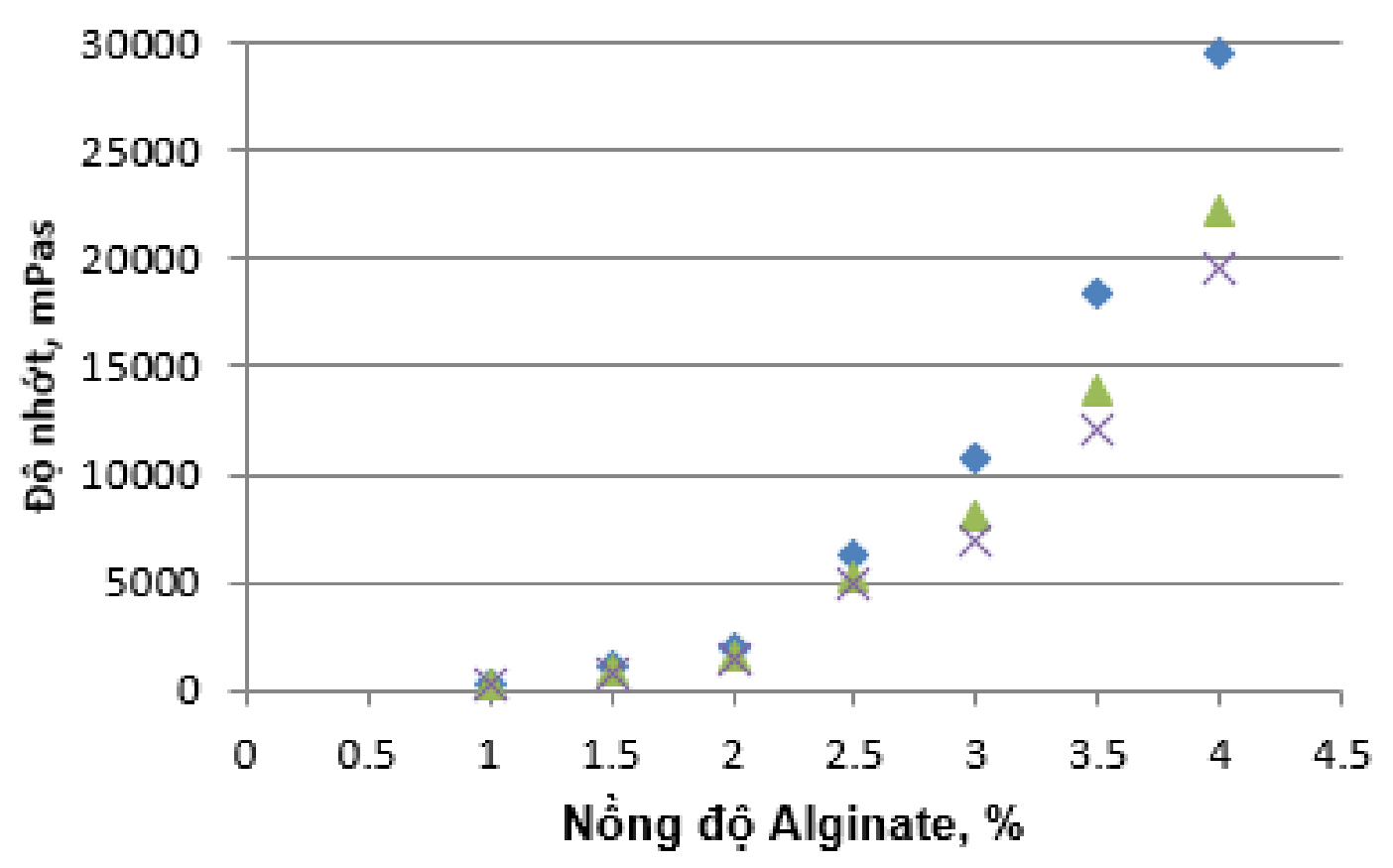

Hình 4. Ảnh hưởng của nồng độ Alginate đến độ nhớt dịch, với m là chỉ số độ đặc $\left(\mathrm{mPas}^{\mathrm{n}}\right)$.

thu cực đại tại 295 nm được chọn để phân tích tinh dầu trong các mẫu hạt vi bọc.

Đường chuẩn hấp thu tinh dầu chanh ở bước sóng 295 nm cho trên Hình 3.

\section{2. Ảnh hưởng của nồng độ Alginate đến độ nhớt dịch, kích thước và độ cầu hạt vi bọc}

\subsection{1. Độ nhớt dịch alginate}

Độ nhớt các dịch alginate (dùng alg2) có đặc tính tăng theo tốc độ cắt (Hình 4) với $\mathrm{n}$ từ 0,7 - 0,85 (Hình 5) nên dịch alginate thuộc loại chất lỏng phi-Newton dạng pseudoplastic, tức độ nhớt giảm khi tăng tốc độ cắt. Kết quả này giống như nhận xét của các tác giả khác (Prüße \& ctv., 2008, Wandrey \& ctv., 2010). Độ nhớt tăng rất nhanh khi tăng nồng độ alginate. Ở $1 \%$ độ nhớt là 242 $\mathrm{mPas}$ và $263 \mathrm{mPas}$ ở tốc độ cắt $5 / \mathrm{s}$ và $3 / \mathrm{s}$, chỉ số độ đặc m là $315.6 \mathrm{mPasn}$. Các giá trị độ nhớt này tăng lên gấp 3 lần, 20 lần và 90 lần khi tăng nồng độ lên $1,5 \%, 2,5 \%$, và $4 \%$ theo thứ tự.

Bảng 1 cho kết quả so sánh giá trị độ nhớt trong nghiên cứu này với các phòng thí nghiệm trên thế giới cho thấy khá tương đương. Độ nhớt trong nghiên cứu này cao hơn một ít do nhiệt dộ đo ở $25^{0} \mathrm{C}$ thấp hơn so với Bratislava \& Brussels 


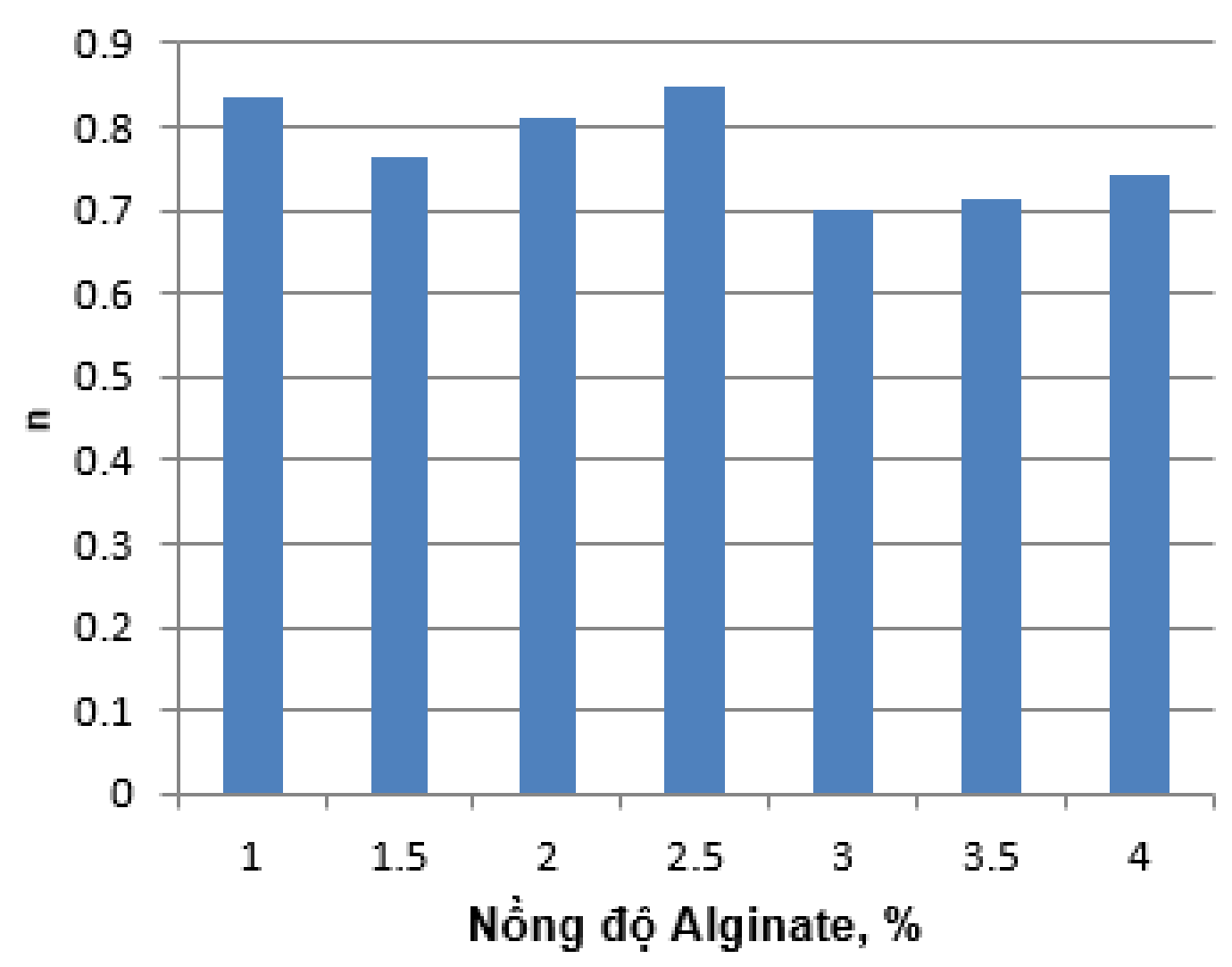

Hình 5. Ảnh hưởng của nồng độ Alginate đến đặc tính dòng chảy n.

(đo ở $30^{0} \mathrm{C}$ ) là hợp lý vì độ nhớt giảm khi tăng nhiệt độ.

\subsubsection{Kích thước, độ cầu hạt}

Đặc tính hình học hạt alginate-Ca vi bọc tinh dầu chanh cho trên Bảng 2 và Hình 6 . Khi tăng nồng độ từ $1 \%$ lên $2,5 \%$ thì đường kính hạt tăng lên từ $1,28 \mathrm{~mm}$ đến $1,57 \mathrm{~mm}$, đồng thời giọt có khối lượng lớn hơn. Tuy nhiên, khi tăng lên trên $2,5 \%$ thì kích thước hạt nhỏ lại và thấp nhất 1,27 mm ở $3,5 \%$ có thể do độ nhớt tăng rất lớn cân bằng lại trọng lượng hạt nên hạt có xu hướng dài ra trước khi rơi. Ở nồng độ $4 \%$ hạt có một cái cuống dài trước khi đứt và rơi xuống. Trong nghiên cứu này dùng kim có đường kính ngoài 0,51 mm cho kích thước hạt vi bọc 1,3 - 1,6 mm nhỏ hơn của tác giả Chan \& ctv. (2009) đo là 2 mm dùng kim 0,4 mm. Kích thước hạt càng nhỏ thì càng dễ áp dụng trong phân phối hoạt chất
(Paulo \& ctv., 2017).

Độ cầu tăng dần từ nồng độ $1 \%$ và đạt tốt nhất 0,985 ở nồng độ $3 \%$ phù hợp cho phương pháp nhỏ giọt kim tiêm (Bảng 2 ). Ở nồng độ $2 \%$ đến $3 \%$ có độ cầu lớn hơn 0,95 nên hạt được xem là hình cầu (Chan \& ctv., 2009). Độ cầu giảm nhanh ở 3,5\% và chỉ còn 0,7 ở nồng độ $4 \%$, không phù hợp cho phương pháp nhỏ giọt kim tiêm. Lúc này phương pháp tạo hạt kiểu dòng tia có đĩa cắt (Jetcutter) sẽ phù hợp (Prüße \& ctv., 2002, 2008). Độ cầu tính theo Chan \& ctv. (2009) tăng lên so với công thức của Mohsenin (1970) từ 0,4 - 5\%. Độ cầu cao chênh lệch ít và độ cầu thấp chênh lệch nhiều giữa 2 công thức. Giá trị độ cầu càng cao thì sự kiểm soát tốc độ phóng thích càng chính xác, dễ ứng dụng trong thực tế (Chan \& ctv., 2009). 


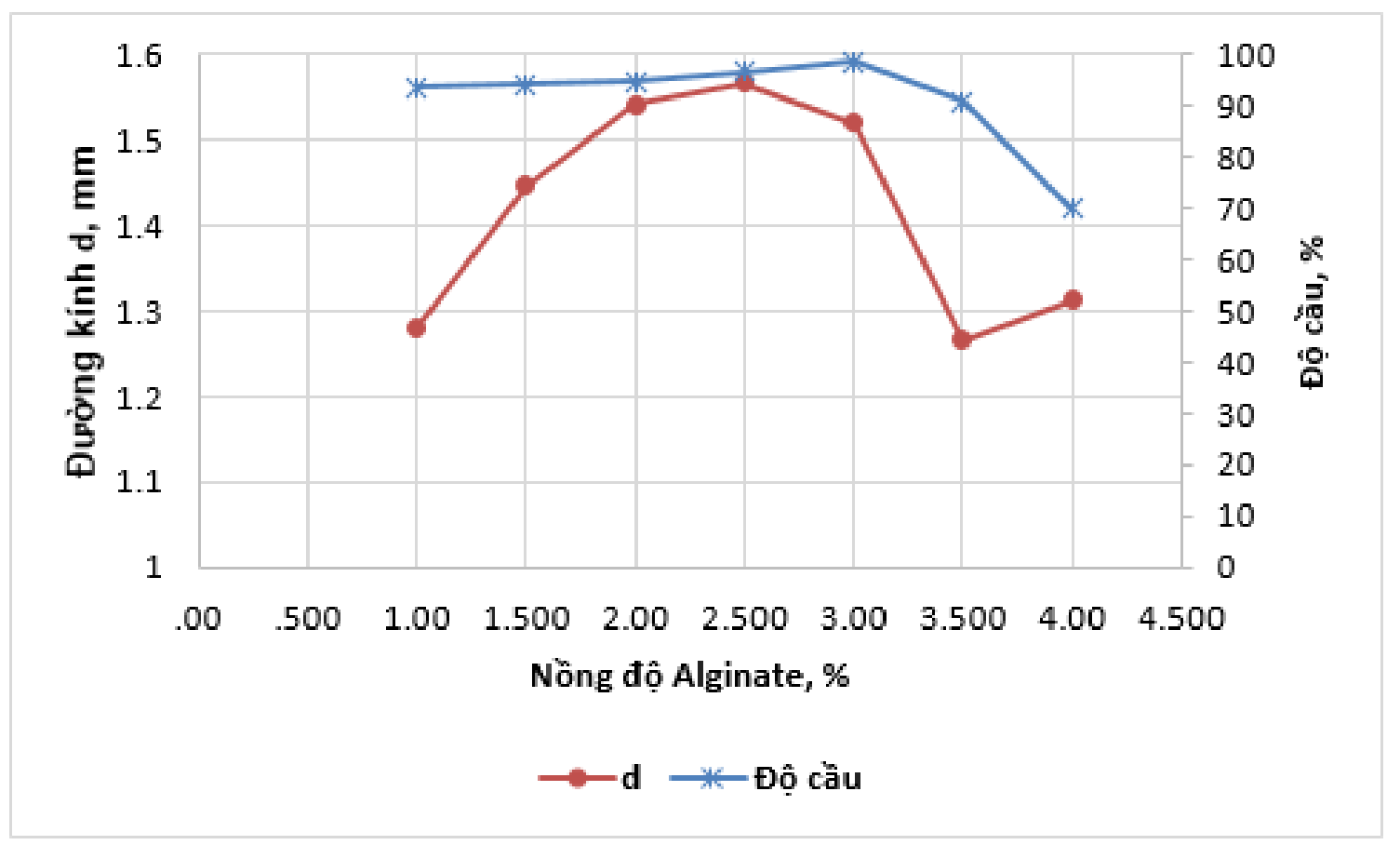

Hình 6. Ảnh hưởng của nồng độ alginate lên đường kính và độ cầu hạt.

\subsubsection{Sức căng bề mặt giọt}

Sức căng bề mặt $\gamma(\mathrm{mN} / \mathrm{m})$ của dịch alginate được tính theo công thức sau (Lewis, 2006), trong đó $\mathrm{m}$ là khối lượng giọt $\left(\mathrm{kg} / \mathrm{m}^{3}\right)$ và $\mathrm{r}$ là bán kính ngoài ống mao dẫn, $\mathrm{F}=0,61$ là hệ số hiệu chỉnh tìm được trong nghiên cứu này, kết quả cho trên Bảng 3.

$$
\gamma=\mathrm{Fmg} / \pi \mathrm{r}
$$

Sức căng bề mặt tăng dần và đạt cực đại ở nồng độ alginate $2 \%$ sau đó giảm dần dền thấp nhất ở nồng độ $4 \%$. Sức căng bề mặt giảm dần theo thứ tự dịch alginate, dịch alginate + Tween, nhũ tương alginate + Tween + tinh dầu. Giá trị sức căng bề mặt của dịch alginate có $1 \%$ Tween 80 khá gần kết quả đo của Chan \& ctv. (2009). Tuy nhiên, Chan \& ctv. (2009) cho thấy sức căng bề mặt giảm dần khi tăng nồng độ dịch từ $0,5-$ $4 \%$, không giống với kết quả của nghiên cứu này là sức căng bề mặt đạt cực đại ở nồng độ alginate $2 \%$ do khối lượng hạt đạt cực đại ở $2 \%$ (công thức (12)).

\subsubsection{Dự đoán đường kính hạt}

Đường kính hạt vi bọc $\mathrm{dp}$ có thể dự đoán từ phương trình do Chan \& ctv. (2009) cải biên từ Poncelet \& ctv. (1999) như sau, trong đó $\mathrm{d}_{\mathrm{T}}, \gamma, \rho$ lần lượt là đường kính ngoài kim $(\mathrm{mm})$, sức căng bề mặt dịch $(\mathrm{mN} / \mathrm{m})$ và khối lượng riêng dịch $\left(\mathrm{kg} / \mathrm{m}^{3}\right)$. Hệ số co rút $\mathrm{k}_{\mathrm{SF}}=0,81$ biểu thị sự co rút từ giọt thành hạt gel, hệ số tổn thất $\mathrm{k}_{\mathrm{LF}}$ tính theo $\mathrm{d}_{\mathrm{T}}$ (Chan \& ctv. 2009).

$$
\begin{gathered}
\mathrm{d}_{\rho}=\mathrm{k}_{\mathrm{LF}} \mathrm{k}_{\mathrm{SF}}\left(\frac{0,006 d_{\mathrm{T} \gamma}}{\rho \mathrm{g}}\right)^{\frac{1}{3}} \\
\mathrm{k}_{\mathrm{LF}}=0,98-0,04 \mathrm{~d}_{\mathrm{T}}
\end{gathered}
$$

Kết quả so sánh với đo đạt trong thí nghiệm này cho trên Hình 7 . Kích thước dự đoán theo Chan \& ctv. (2009) lớn hơn đo khoảng 30 - 57\%. Kích thước dự đoán phù hợp kết quả đo của Chan \& ctv. (2009) nhưng lớn hơn nhiều so với trong bài báo này có lẽ do khác biệt của nguyên liệu alginate, nồng độ $\mathrm{CaCl}_{2}$ của Chan \& ctv. (2009) là $10 \mathrm{mM}$ và nghiên cứu này là $15 \mathrm{mM}$. 
Bảng 2. Đặc tính hình học của hạt alginate-Ca vi bọc tinh dầu chanh ở năng suất tải $22 \%$, dùng Alg2 (hình chụp bằng kính hiển vi Leica DM2500P)

\begin{tabular}{|c|c|c|c|}
\hline Nồng độ alginate, $\%$ & Hình dạng & Đường kính tương đương ${ }^{1}, \mathrm{~mm}$ & Độ cầu ${ }^{1}$ \\
\hline 1 & & $1,28 \pm 0,04$ & $0,935 \pm 0,057$ \\
\hline 1.5 & & $1,45 \pm 0,06$ & $0,943 \pm 0,040$ \\
\hline 2 & & $1,54 \pm 0,04$ & $0,950 \pm 0,020$ \\
\hline 2.5 & & $1,57 \pm 0,03$ & $0,966 \pm 0,013$ \\
\hline 3 & & $1,52 \pm 0,01$ & $0,985 \pm 0,010$ \\
\hline 3.5 & & $1,27 \pm 0,03$ & $0,907 \pm 0,028$ \\
\hline 4 & & $1,31 \pm 0,03$ & $0,699 \pm 0,057$ \\
\hline
\end{tabular}

${ }^{1}$ Số liệu trung bình $\pm \mathrm{SD}$, đo từ 10 hạt. 
Bảng 3. Kết quả sức căng bề mặt $(\mathrm{mN} / \mathrm{m})$

\begin{tabular}{|c|c|c|c|c|}
\hline $\begin{array}{l}\text { Nồng độ } \\
\text { alginate, \% }\end{array}$ & Dịch Alginate & $\begin{array}{c}\text { Dịch Alginate + } \\
\text { Tween }\end{array}$ & $\begin{array}{c}\text { Nhũ tương } \\
\text { Alginate }+ \\
\text { Tween + tinh } \\
\text { dầu }\end{array}$ & $\begin{array}{c}\text { Dịch Alginate, } \\
\text { (Chan \& ctv. } \\
2009)\end{array}$ \\
\hline 0.5 & - & - & - & 71 \\
\hline 1 & $88,3 \pm 0,2$ & $71,9 \pm 0,1$ & $55,9 \pm 0,2$ & \\
\hline 1.5 & $90,2 \pm 0,3$ & $75,6 \pm 0,2$ & $57,8 \pm 0,3$ & 70 \\
\hline 2 & $90,5 \pm 0,1$ & $78,7 \pm 0,2$ & $59,6 \pm 0,3$ & \\
\hline 2.5 & $90,3 \pm 0,2$ & $74,7 \pm 0,1$ & $57,3 \pm 0,2$ & 69 \\
\hline 3 & $88,3 \pm 0,3$ & $74,8 \pm 0,3$ & $55,2 \pm 0,1$ & \\
\hline 3.5 & $88,1 \pm 0,1$ & $64,9 \pm 0,4$ & $52,3 \pm 0,2$ & \\
\hline 4 & $76,6 \pm 0,2$ & $59.3 \pm 0.3$ & $36,7 \pm 0,1$ & 57 \\
\hline
\end{tabular}

Số liệu đo là trung bình $\pm \mathrm{SD}$ của 10 giọt, số liệu tham khảo không có $\mathrm{SD}$ ).

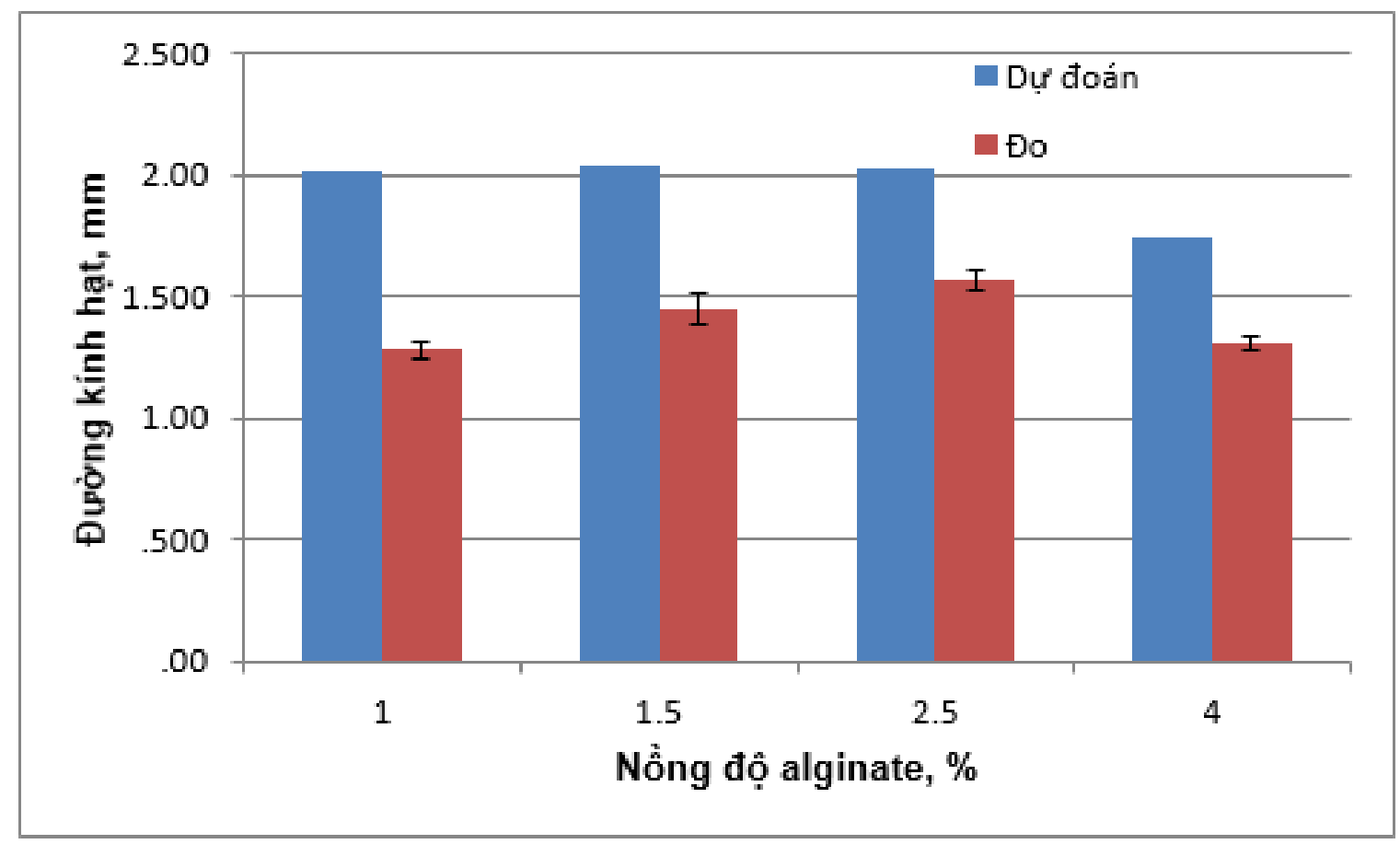

Hình 7. So sánh đường kính hạt vi bọc đo và dự đoán. Nguồn: Chan \& ctv. (2009).

3.2.5. Ảnh hưởng của nguyên liệu Alginate đến chất lượng vi bọc tinh dầu chanh

Qua khảo sát độ nhớt cho thấy vật liệu alg1 ít nhớt hơn alg2. Cụ thể độ nhớt dịch alg1 ở nồng độ $3 \%$ tương đương với dịch alg2 ở nồng độ 1,5\%. Hạt vi bọc tinh dầu chanh ứng với hai nồng độ alginate này được so sánh các chỉ tiêu hiệu suất, hiệu quả, khả năng tải và hiệu suất thu hồi chất rắn (Bảng 4).

Bảng 4 cho thấy hiệu suất vi bọc hai hoại al- ginate tương đương nhau trong khoảng $73-74 \%$. Hiệu quả vi bọc alg1 cao hơn alg2 chứng tỏ có nhiều tinh dầu chanh dính trên bề mặt alg2 hơn alg1. Năng suât tải thực tế alg1 là 43,53\% cao hơn rất nhiều so với năng suất tải thiết kế $22 \%$ do hiệu suất thu hồi chất rắn alg1 chỉ 52,17\% nghĩa là mất đi $48 \%$ vật chất trong nguyên liệu vì có nhiều tạp chất. Trong lúc đó, năng suất tải thực tế của alg2 là 20,27\% gần với năng suất tải thiết kế $22 \%$ do có hiệu suất thu hồi chất rắn đến 98,99\%, chỉ mất 1,01\% vật chất trong nguyên liệu 
Bảng 4. So sánh đặc tính vi bọc tinh dầu chanh của 2 loại alginate

\begin{tabular}{lcc}
\hline Chỉ tiêu & Alg1 & Alg2 \\
\hline Hiệu suất vi bọc, $\%$ & $74,52 \pm 0,07$ & $73,32 \pm 1,32$ \\
Hiệu quả vi bọc, $\%$ & $86,67 \pm 1,68$ & $78,58 \pm 0,23$ \\
Năng suất tải hạt khô, $\%$ & $43,53 \pm 0,03$ & $20,27 \pm 0,07$ \\
Năng suất tải hạt tươi, $\%$ & $1,85 \pm 0,13$ & $0,60 \pm 0,02$ \\
Hiệu suất thu hồi chất rắn, $\%$ & $52,17 \pm 0,04$ & $98,99 \pm 0,02$ \\
Ầm độ hạt, \% wb & $95,7 \pm 0,10$ & $97,02 \pm 0,05$ \\
\hline
\end{tabular}

chứng tỏ alg2 tinh khiết hơn. Trong sản xuất, alg1 thải ra môi trường nhiều chất hữu cơ cần phải xử lý hơn alg2.

\section{Kết Luận}

Tinh dầu chanh được vi bọc bằng phương pháp ion-gel tạo hạt bằng kỹ thuật nhỏ giọt kim tiêm. Alginate được sử dụng làm polymer có ion âm để liên kết với ion dương của calcium. Khảo sát cho thấy độ nhớt của dịch alginate có dạng phiNewton kiểu giả dẽo (pseudoplastic). Độ nhớt tăng rất nhanh khi tăng nồng độ dịch. Điều này ảnh hưởng đến khả năng tạo hình cầu của hạt alginate-Ca. Phương pháp nhỏ giọt kim tiêm có thể tạo hạt có độ cầu trên $95 \%$ và kích thước 1,5 - 1,6mm ở dịch có nồng độ 2 - $3 \%$ là nồng độ mà phương pháp rung dòng tia không tạo được hạt. Phương pháp nhỏ giọt kim tiêm không thể tạo hình cầu khi nồng độ alginate từ $3,5 \%$ trở lên.

Nguyên liệu alginate có ảnh hưởng đến chất lượng và đặc tính vi bọc tinh dầu chanh. Hai nguyên liệu alginate có độ tinh khiết khác nhau nhưng hiệu suất vi bọc tương đương nhau. Tuy nhiên, vật liệu có nhiều tạp chất có hiệu suất thu hồi chất rắn thấp hơn $45 \%$ so với vật liệu có độ tinh khiết cao. Trong quá trình sản xuất, nguyên liệu alginate tinh khiết sẽ thải ít chất hữu cơ hơn nên giảm công xử lý nước thải. Ngoài ra, nguyên liệu alginate tinh khiết hơn sẽ cho năng suất tải tinh dầu thực tế gần với thiết kế hơn nên dễ kiểm soát hàm lượng hoạt chất hơn.

\section{Tài Liệu Tham Khảo (References)}

Anitha, K., Ramachandran, T., Rajendran, R., \& Mahalakshmi, M. (2011). Microencapsulation of lemon grass oil for mosquito repellent finishes in polyester textiles. Elixir Bio Physics 40, 5196-5200.

Chan, E. S. (2011). Preparation of Ca-alginate Beads contain-ing high oil content: influence of process variables on encapsulation efficiency and bead properties. Carbo-hydrate Polymers 84(4), 1267-1275.
Chan, E. S., Lee, B. B., Ravindra, P., \& Poncelet, D. (2009). Prediction models for shape and size of ca-alginate macrobeads produced through extrusion-dripping method. Journal of Colloid and Interface Science 338, 63-72.

Kausadikar, S., Ashish, D. G., \& Jyotsna, W. (2015). Microencapsulation of lemon oil by spray drying and its application in flavour tea. Advances in Applied Science Research 6(4), 69-78.

Lewis, M. J. (2006.) Physical properties of foods and food processing systems. Sawston, England: Woodhead Publishing.

Martins, I. M., Maria, F. B., Manuel, C., \& Alírio, E. R. (2014). Microencapsulation of essential oils with biodegradable polymeric carriers for cosmetic applications. Chemical Engineering Journal 245, 191-200.

Mohsenin, N. N. (1970). Physical properties of plant and animal materials. New York, USA: Gordon and Breach Science Publishers.

Park, S. J., Shin, Y. S., \& Lee, J. R. (2001). Preparation and characterization of microcapsules containing lemon oil. Journal of Colloid and Interface Science 241, 502-508.

Paulo, B. B., Ramos, F. D. M., \& Prata, A. S. (2017). An investigation of operational parameters of jet cutting method on the size of Ca-alginate beads. Journal of Food Process Engineering, 1-8.

Poncelet, D., Babak, V. G., Neufeld, U. R. J., Goosen, M. F. A., \& Burgarski, B. (1999). Theory of electrostatic dispersion of polymer solutions. Advances in Colloid and Interface Science 79, 213-228.

Prüße, U., Luca, B., Marek, B., Branko, B., Jozef, B., Peter, G., Dorota, L., Verica, M., Benjamin, M., Claudio, N., Viktor, N., Poncelet, D., Swen, S., Lucien, T., Azzurra, T., Alica V., \& Klaus-Dieter V. (2008). Comparison of different technologies for alginate beads production. Chemical Papers 62(4), 364-374.

Prüße, U., Ulrich, J., Peter, W., Jürgen, B., \& KlausDieter, V. (2002). Bead production with JetCutting and rotating disc/nozzle technologies. In Prüße, U. \& Klaus-Dieter, V. (Eds.). Practical Aspects of Encapsulation Technologies Proceedings on 2001, Braunschweig, Germany. 
Soliman, E. A., El-Moghazy, A. Y., El-Din, M. M., \& Massoud, M. A. (2013). Microencapsulation of essential oils within alginate: Formulation and in vitro evaluation of antifungal activity. Journal of Encapsulation and Adsorption Sciences 3, 48-55.

Wandrey, C., Artur, B., \& Stephen, E. H. (2010). Materials for Microencapsulation. In Nicolaas, J. Z., \& Nedovic, A. V. (Ed.). Encapsulation technologies for active food ingredients and food processing. (31-100). New York City, America: Springer Publication.
Wandrey, C., Artur, B., \& Stephen, E. H. (2010). Materials for microencapsulation. In Nicolaas, J. Z., \& Nedovic, A. V. (Eds.). Encapsulation technologies for active food ingredients and food processing (31-100). New York, USA: Springer. 